\title{
Surgical Treatment Outcomes of Acquired Benign Tracheoesophageal Fistula: A Literature Review
}

\author{
Sang Pil Kim, M.D. ${ }^{1}$, Juhyun Lee, M.D. ${ }^{2}$, Sung Kwang Lee, M.D. ${ }^{2}$, Do Hyung Kim, M.D. ${ }^{3}$ \\ 'Department of Thoracic and Cardiovascular Surgery, Ewha Womans University Seoul Hospital, Seoul; ${ }^{2}$ Department of Thoracic and Cardiovascular Surgery, Inje \\ University Busan Paik Hospital, Busan; ${ }^{3}$ Department of Thoracic and Cardiovascular Surgery, Pusan National University School of Medicine, Yangsan, Korea
}

\section{ARTICLE INFO}

Received February 1, 2021

Revised March 24, 2021

Accepted March 24, 2021

Corresponding author

Do Hyung Kim

Tel 82-55-360-2127

Fax 82-55-360-2127

E-mail yumccs@nate.com

ORCID

https://orcid.org/0000-0002-8774-3397
Background: Tracheoesophageal fistula (TEFs) is a rare condition that requires complex surgical treatment. We analyzed the surgical outcomes of TEF reported in the literature and at Pusan National University Yangsan Hospital using standardized techniques.

Methods: This retrospective study included 8 patients diagnosed with acquired benign TEF between March 2010 and December 2019. The surgical method was determined based on the size of the fistula observed within the endoscope.

Results: TEF occurred in 7 patients (87.5\%) after intubation or tracheostomy and in 1 patient (12.5\%) after esophageal surgery due to conduit necrosis. For tracheal management, 5 and 2 patients underwent tracheal resection and end-to-end anastomosis and primary repair, respectively. The median length of resection was $2.5 \mathrm{~cm}$ (range, 1.3-3.4 cm). For esophageal management, 6 patients underwent primary repair and 1 patient underwent esophageal diversion. One patient underwent TEF division with a stapler. Interposition of a muscle flap was performed in 2 patients. TEF recurrence, esophageal stenosis, and dehiscence or granulation occurred in 1, 1, and 2 patients, respectively. A long-term tracheostomy tube or T-tube was used in 2 patients for $>2$ months.

Conclusion: Although TEF surgery is complex and challenging, good results can be achieved if surgical standards are established and experience is accumulated.

Keywords: Tracheoesophageal fistula, Trachea, Esophagus, Tracheal resection

\section{Introduction}

Spontaneous closure of a tracheoesophageal fistula (TEF) is uncommon, and surgical treatment is required in most cases. Alternative interventions such as stent insertion or clipping can be used, but these interventions are applicable only for small fistulas. For large TEFs presenting with typical symptoms, alternative interventions are often difficult and surgery is required [1-3].

Limited studies have reported the surgical outcomes of TEF because the condition is relatively rare and a complex surgical technique is required. Moreover, with the recent introduction of the low-pressure high-volume endotracheal tube, the occurrence of TEF as a consequence of endotracheal balloon compression has decreased, which in turn has reduced the need for surgical intervention [4]. With the development of medical support and advances in surgical techniques compared to the past, TEF surgery is becoming safer. Although many doctors agree that surgical treatment is appropriate for TEF, there remains a lack of consensus regarding the standard surgical procedure. Since there is no established standard for each aspect of surgery, such as the indications of surgery, the surgical approach, the procedure for the trachea and esophagus, and the application of the flap, surgeons have different methods and criteria for applying treatment. At several institutions, surgical methods have also changed over time. However, a standard protocol for surgery needs to be established to standardize the surgical technique, especially at institutions that have limited experience in TEF surgery, and there has been no leading group in this regard. Therefore, the present study aimed to analyze the results of TEF operation reported in the literature and to compare the surgical results obtained at our small-volume center to those of other centers to help 
obtain better clinical results in the future.

\section{Methods}

\section{Patient selection}

We retrospectively reviewed the clinical data of 8 adult patients diagnosed with acquired benign TEF at our clinic between March 2010 and December 2019. The medical records were reviewed for demographic information, the cause of TEF, preoperative medical condition, comorbidities, prior surgery, operative procedures, length of hospitalization, morbidity, and mortality. Operative mortality included all deaths occurring within 30 days of the prescribed procedure. Follow-up was performed by chart review or a telephonic survey to investigate late complications.

The appropriate surgical intervention was determined by the cause and size of TEF (examined by gastric endoscopy) and a reported history of persistent pulmonary aspiration. Regardless of its size, if the extent of the fistula was such that the tracheal tube was visible through the gastric endoscope, it was defined as surgically appropriate to select tracheal resection and end-to-end anastomosis (TREE) with primary esophageal closure. Fistula division and primary repair of the trachea and esophagus were performed when the endotracheal tube was not visible if the fistula was small. Additionally, if the fistula was too large for TREE, division and primary repair were performed. This study was reviewed and approved by the Institutional Review Board of Pusan National University Yangsan Hospital (IRB approval no., L-2021-30). The recommendations of the Declaration of Helsinki for biomedical research involving human subjects were followed. The requirement for informed consent was waived.

\section{Operative techniques}

\section{TREE with primary esophageal closure}

After a U-shaped cervical incision, midline dissection was performed between the 2 sternohyoid muscles, and then the thyroid isthmus was divided to expose the anterior surface of the trachea. The trachea was dissected circumferentially above and below the site of the fistula and as close as possible to the outer tracheal surface to prevent recurrent laryngeal nerve injury. The trachea was then divided below and above the site of the fistula. Once the distal airway was separated, a new endotracheal tube was inserted into the distal tracheal airway through the surgical wound. The original endotracheal tube was then with- drawn to the proximal trachea by the anesthetist. After securing the airway, the trachea containing the fistula lesion was removed, except for the posterior membranous portion. Resection of the trachea allowed complete exposure of the esophageal defect (Fig. 1A). The edges of the esophageal defect were debrided and a double-layer closure was made (Fig. 1B). After the esophageal defect was repaired, the posterior membranous portion of the trachea was reconstructed with continuous 4-0 polydioxanone (PDS) sutures (Ethicon Inc., Somerville, NJ, USA). After posterior anastomosis of the airway was completed, the endotracheal tube inserted in the trachea (distal) was removed, the tube located above was placed under the tracheal anastomosis, and mechanical ventilation was maintained. Several interrupted 4-0 PDS sutures were then added anteriorly (Fig. 1C). Laryngeal release was performed and the neck was flexed to avoid excessive anastomotic tension. During TREE and primary esophageal repair, additional muscle flap interposition was not performed because the location of esophageal closure and airway anastomosis were different regardless of the length of tracheal resection.

\section{Fistula division and direct closure of the tracheal and esophageal defects}

TEF exposure was performed via a lateral oblique incision at the left sternocleidomastoid muscle. The sternocleidomastoid muscle was dissected to expose the jugular vein, carotid artery, and thyroid gland. The thyroid gland and

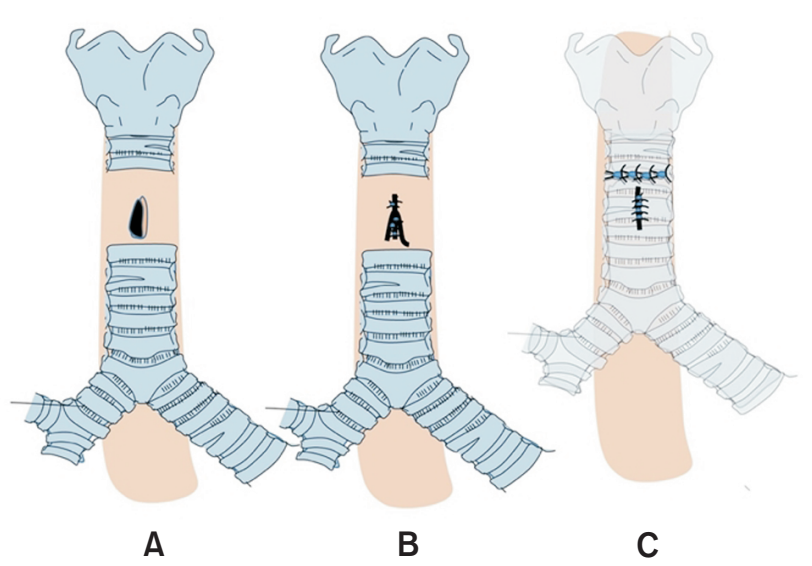

Fig. 1. Schematic diagram of tracheal resection and end-to-end anastomosis. (A) The trachea is resected below and above the site of the fistula. The fistulous site in the esophagus is exposed between the proximal trachea and distal trachea. (B) The edges of the esophageal defect are debrided and a double-layer closure is made. (C) Because the repair site of the esophageal defect and the anastomosis site of trachea reconstruction are located at different levels, an additional muscle flap interposition is not performed. 
trachea were pulled forward and contralaterally. To ensure that the recurrent laryngeal nerve was not accidentally dissected, the nerve was identified and it was ensured that the nerve was located far from the fistula. The fistulous tract was then dissected and divided (Fig. 2A). Closure of the membranous tracheal defect was performed directly with interrupted 4-0 PDS sutures. The esophageal defect was then closed by a double layer after debridement of the fistulous edges (Fig. 2B). To avoid close contact with both repair sites, a flap of strap muscle was interposed between the esophagus and trachea (Fig. 2C). However, in 1 case, tracheal resection was impossible because the fistula size was $>5 \mathrm{~cm}$; hence, division using a stapler was performed (Fig. 2D).

\section{Statistical analysis}

Continuous data are expressed as median values and interquartile ranges. All statistical analyses were performed using IBM SPSS ver. 21.0 software (IBM Corp., Armonk, NY, USA).
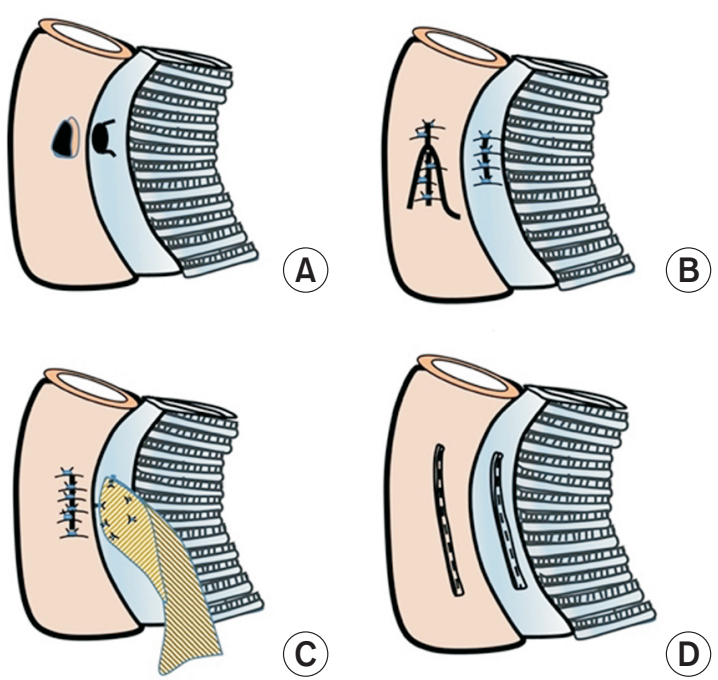

C)

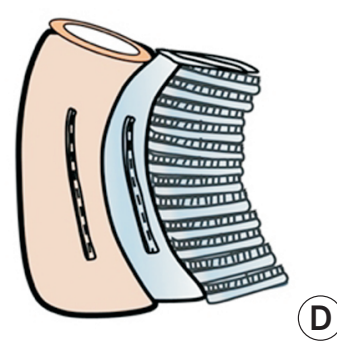

Fig. 2. Schematic diagram of fistula division and direct closure of the tracheal and esophageal defect. (A) The fistulous tract is divided and the fistula between the esophagus and trachea is exposed. (B) The membranous tracheal defect is closed directly with interrupted sutures. The esophageal defect is closed by a double layer. (C) To avoid close contact with both repair sites, a flap of strap muscle is interposed between the esophagus and trachea. (D) In 1 case, division of the fistula was performed using a stapler due to a large fistula $(>5 \mathrm{~cm})$. We decided that the fistula would be divided by a stapler as a modification of primary repair. Tracheal resection was impossible because the fistula size was $>5 \mathrm{~cm}$; hence, division using a stapler was performed.

\section{Results}

\section{Perioperative characteristics of patients}

Between January 2010 and December 2019, 8 patients were diagnosed with TEF and underwent surgical treatment. The median age of the 8 patients was 58.5 years (range, 38.3-77.5 years). Of the patients, 3 were men and 5 were women. The median body mass index of the $8 \mathrm{pa}-$ tients was $22.2 \mathrm{~kg} / \mathrm{m}^{2}$ (range, $20.0-28.4 \mathrm{~kg} / \mathrm{m}^{2}$ ). TEF occurred in 7 patients $(87.5 \%)$ after intubation or tracheostomy and in 1 patient (12.5\%) after esophageal surgery due to conduit necrosis. Six patients $(75 \%)$ had a preoperative tracheostomy and 2 patients (25\%) were not intubated. Preoperatively, 2 patients (25\%) were placed on a mechanical ventilator. The median period from diagnosis to surgery was 5 days (range, 1.3-19.3 days) (Table 1).

\section{Postoperative results}

The surgical procedure was performed through the cervical approach in 7 patients $(87.5 \%)$ and the thoracic approach in 1 patient (12.5\%). For tracheal management, 5 (65.5\%), 2 (25\%), and 1 (12.5\%) patient underwent TREE, primary repair, and division with a stapler, respectively. The median length of resection was $2.5 \mathrm{~cm}$ (range, $1.3-3.4 \mathrm{~cm}$ ).

Table 1. Perioperative characteristics of patients $(n=8)$

\begin{tabular}{lc}
\hline \multicolumn{1}{c}{ Characteristic } & Value \\
\hline Age $(\mathrm{yr})$ & $58.5(38.3-77.5)$ \\
Sex & $3(37.5)$ \\
$\quad$ Male & $5(62.5)$ \\
Female & $22.2(20.0-28.4)$ \\
Body mass index $\left(\mathrm{kg} / \mathrm{m}^{2}\right)$ & \\
Cause & $7(87.5)$ \\
$\quad$ Post-intubation or tracheostomy TEF & $1(12.5)$ \\
Post-esophageal surgery, conduit necrosis & \\
Preoperative intubation state & $6(75.0)$ \\
Tracheostomy & 0 \\
Intubation & $2(25.0)$ \\
$\quad$ None & $2(25.0)$ \\
Preoperative mechanical ventilation & \\
Comorbidity & $4(50.0)$ \\
Cerebrovascular & 0 \\
Cardiovascular & $1(12.5)$ \\
Respiratory disease & $4(50.0)$ \\
Others & 0 \\
Other preoperative treatment for TEF & $5(1.3-19.3)$ \\
\hline Time from diagnosis to surgery (day) & \\
\hline Values are presented &
\end{tabular}

Values are presented as median (range) or number (\%).

TEF, tracheoesophageal fistula. 
Six patients (75\%) underwent primary repair, 1 patient (12.5\%) underwent division with a stapler, and 1 patient (12.5\%) underwent esophageal diversion treatment. Interposition of a muscle flap was performed in 2 patients (25\%). The median operation time was 177.5 minutes (range, 108.8-335.0 minutes). The median estimated blood loss was $100 \mathrm{~mL}$ (range, $50-237.5 \mathrm{~mL}$ ). The median duration of postoperative mechanical ventilation was 1.5 days (range, $0.3-2.8$ days). The median length of intensive care unit and hospital stays were 6 days (range, 2.3-23.8 days) and 33.5 days (range, 18.5-173.5 days), respectively. Morbidity occurred in 4 patients (50\%). TEF recurred in 1 patient (12.5\%). Stenosis of the esophagus occurred in 1 patient (12.5\%). Dehiscence or granulation occurred in 2 patients (25\%). A long-term tracheostomy tube or T-tube was used in 2 patients $(25 \%)$ for $>2$ months. There were no instances of mortality within 30 days postoperatively, and all patients were discharged successfully (Table 2).

Table 2. Postoperative results

\begin{tabular}{|c|c|}
\hline Variable & Value \\
\hline \multicolumn{2}{|l|}{ Approach } \\
\hline Cervical & $7(87.5)$ \\
\hline Thoracotomy & $1(12.5)$ \\
\hline \multicolumn{2}{|l|}{ Trachea management } \\
\hline Tracheal resection and end-to-end anastomosis & $5(65.5)$ \\
\hline Primary repair & $2(25.0)$ \\
\hline Division with stapler & $1(12.5)$ \\
\hline Resection length (cm) & $2.5(1.3-3.4)$ \\
\hline \multicolumn{2}{|l|}{ Esophageal treatment } \\
\hline Primary repair & $6(75.0)$ \\
\hline Stapling & $1(12.5)$ \\
\hline Diversion & $1(12.5)$ \\
\hline Other concomitant operation & $2(25.0)$ \\
\hline Muscle flap interposition & $2(25.0)$ \\
\hline Operation time (min) & $177.5(108.8-335.0)$ \\
\hline Estimated blood loss (mL) & $100.0(50.0-237.5)$ \\
\hline Postoperative bleeding (mL for 24 hours) & $50.0(5.0-81.3)$ \\
\hline Mechanical ventilation (day) & $1.5(0.3-2.8)$ \\
\hline Intensive care unit stay (day) & $6.0(2.3-23.8)$ \\
\hline Hospital stay (day) & $33.5(18.5-173.5)$ \\
\hline 30-Day mortality & 0 \\
\hline Morbidity & $4(50.0)$ \\
\hline \multicolumn{2}{|l|}{ Complications } \\
\hline Tracheoesophageal fistula recurrence & $1(12.5)$ \\
\hline Stenosis & $1(12.5)$ \\
\hline Dehiscence or granulation & $2(25.0)$ \\
\hline Vocal cord palsy & 0 \\
\hline Pneumonia or respiratory failure & $1(12.5)$ \\
\hline Long-duration tracheostomy or T-tube & $2(25.0)$ \\
\hline
\end{tabular}

Values are presented as number (\%) or median (range).

\section{Discussion}

Surgical treatment of TEF has been proposed by Grillo et al. [5] and Mathisen et al. [1] of Massachusetts General Hospital and has been accepted as the standard surgical procedure. Generally, a low collar incision is performed, and in some cases partial sternotomy is added when a fistula is present in the lower airway. Very rarely, a thoracotomy is performed if the fistula is above the carina. The timing of surgery is dependent on the patient's general health factors including recovery from pneumonia, good nutritional status, and ventilator weaning, if necessary. If the patient requires mechanical ventilation, it is preferable to delay the surgery until the patient's medical condition improves substantially. To alleviate aspiration pneumonia caused by gastric juices, it is recommended to empty the stomach and perform gastrostomy and jejunostomy feeding for nutrition.

In primary repair, Macchiarini et al. [6] postulated that both sides of the fistula have a high recurrence rate because the repair sites of the esophagus and the trachea are exposed on opposite sides. However, when TREE is performed, the primary repair site of the esophagus and the tracheal anastomosis site are located at different levels regardless of the length of trachea resection. Therefore, the possibility of fistula recurrence is low. Based on an analysis of 31 cases of TEF surgery over approximately 20 years, TREE was considered the standard procedure. It resulted in a lower incidence of complications (7\% versus $38 \%$ ) and a higher long-term survival rate (93\% versus $65 \%)$ than division and primary repair. In that study, the 2 surgical techniques accounted for the same proportion of cases, but direct closure of the tracheal and esophageal defects was performed in the first half of the study period, while TREE was performed in all cases in the latter half. Considering that the overall ability of the institution to treat TEFs has improved over time, TREE is likely to result in positive surgical results today.

In addition, the surgical records over a 35-year period of the Massachusetts General Hospital group were analyzed by dividing them into 2 groups: the first half of the study period and the second half of the study period [7]. The frequency of tracheal resection decreased in the second half of the period from $82 \%$ to $61 \%$, and the mortality rate decreased from $10.5 \%$ to $2.8 \%$, although the difference was not statistically significant. However, the trachea appliance rate was significantly higher in the second half of the period $(28.6 \%)$ than in the first half of the period (5.8\%). Moreover, the fistula recurrence rate increased from $5.3 \%$ in the 
first half of the period to $11.1 \%$ in the second half of the period. Overall, the risks of surgery decreased, but the overall increase in the trachea appliance rate and the recurrence rate resulted in more frequent failure of surgery. Previous studies that preferred TEF division reported a lower incidence of mortality than those that performed TREE, but the surgical failure rate was high. Moreover, the choice between the 2 surgical methods depended on institutional preferences, rather than specific inclusion criteria. The literature review indicated that primary repair and tracheal resection were performed in $42.9 \%$ and $43.2 \%$ of cases, respectively, and tracheal resection was preferred in 9 of 14 reports (Table 3) [1,6-18].

However, we think it is unreasonable to choose 1 of the 2 surgical methods depending on institutional preferences; hence, objective selection criteria need to be established. The Massachusetts General Hospital group claimed that tracheal resection should be performed if the fistula has a width of $\geq 3 \mathrm{~cm}$ or for circular tracheal injuries. However, the primary repair technique for fistulas measuring $2-3 \mathrm{~cm}$ is controversial. Muniappan et al. [7] and Bibas et al. [8] have suggested that it is reasonable to perform TREE in cases with a fistula measuring $>10 \mathrm{~mm}$.

However, it is difficult to accurately measure the fistula size using either computed tomography or endoscopy preoperatively; hence, obtaining accurate measurements is often problematic. Considering that the approach site and range of the 2 methods are different, it is advised to determine the size of the fistula and accordingly decide the appropriate surgical method before the actual surgery, especially when there is inflammation around the fistula. However, it is possible to determine the surgical method based on endoscopic observations. According to Debourdeau et al. [3], the size of the fistula's orifice examined through gastrointestinal endoscopy can be classified into 3 stages, which can be used to determine the fistula treatment. Stage I is described as "punctiform," if the diameter is less than the diameter of a closed biopsy forceps; stage II is described as "medium," if the size is larger but the bronchus cannot be seen through the fistula's orifice; and stage III is described as "large," if the tracheobronchial tree is seen through the fistula's orifice with the endoscope. Based on these observations, fistula division and tracheal resection may be utilized for fistulas of stages II and III, respectively. It is, thus, recommended that these criteria be applied for patients with TEF in general; however, in exceptional cases, the surgical method should be determined according to the specific case. Dhiwakar et al. [19] proposed a flow chart for surgical decision-making based on a review of descriptions from throughout the world, and suggested that primary repair should be selected if the fistula size is $>5 \mathrm{~cm}$ because it is impossible to perform tracheal resection. We reported 1 such example in the current study. The fistula size confirmed before surgery was about $5 \mathrm{~cm}$; therefore, tracheal resection could not be performed and the risk of anastomotic complications was expected to be high. Therefore, we decided to divide the fistula using a stapler as a modification of primary repair.

Regardless of the method of surgery, most institutions prefer double-layer primary repair as an esophageal repair method. In some cases, if the fistula is large, primary repair of both the esophagus and the trachea is impossible, and 1 site of the 2 organs should be repaired first. In most cases, the esophagus is abandoned and the trachea is repaired first. The abandoned esophagus is reconstructed at 1 stage on the operation date or delayed reconstruction is performed using the stomach or colon several months later $[6,8,9,16-18]$. In the past, in surgery for large fistulas, muscle flap interposition was used for the treatment of acquired TEF. However, muscle flap interposition is no longer widely used as the trachea resection technique has become more common in recent years $[6,14,16]$.

A few notable results were observed in the current study. In cases of TREE, tracheal anastomosis-related complications were observed, such as stenosis and granulation. The complications of primary repair included TEF recurrence. As shown by the Massachusetts General Hospital group, the TEF recurrence rate was low during the first half of the study period, when tracheal resection was the procedure of choice. However, a TEF recurrence rate of $11 \%$ was reported during the second half of the period, with relatively high rates of primary repair [7]. The TEF recurrence rate was relatively high $(8.6 \%)$ in a Mayo Clinic report, where only $9 \%$ of patients underwent tracheal resection. However, a recurrence rate of $<5 \%$ was observed in the group that underwent tracheal resection. Low rates of complications of the repair site of the esophagus have been reported in the literature. Moreover, dehiscence of primary repair has not generally been reported. Most complications were caused by gastric conduit reconstruction after esophageal diversion [16]. As indicated in Table 3, 70\%-100\% of patients who underwent surgery had a muscle flap interposition, which aided in preventing esophageal suture leaks. However, the success of utilizing muscle flap interposition for tracheal resection requires further investigation. Camargo et al. [10] reported that fistula recurrence did not occur although they did not perform muscle flap interposition in the trachea resection group. Postoperative pneumonia 
Table 3. Surgical procedures in various studies on the treatment of tracheoesophageal fistula

\begin{tabular}{|c|c|c|c|c|c|c|c|}
\hline \multirow{2}{*}{ Reference } & \multirow{2}{*}{ Total } & \multicolumn{3}{|c|}{ Trachea } & \multicolumn{2}{|r|}{ Esophagus } & \multirow{2}{*}{$\begin{array}{c}\text { Muscle } \\
\text { interposition }\end{array}$} \\
\hline & & Repair & TREE & Other technique & Repair & Other technique & \\
\hline $\begin{array}{l}\text { Mathisen et al. } \\
\text { [1] (1991) }\end{array}$ & 38 & $9(23.7)$ & $29(76.3)$ & & & $\begin{array}{l}5 \text { (13.2): end to end esophageal } \\
\text { anastomosis }\end{array}$ & $34(89.5)$ \\
\hline $\begin{array}{l}\text { Baisi et al. [18] } \\
\text { (1999) }\end{array}$ & 29 & $26(89.7)$ & $1(3.4)$ & $\begin{array}{l}2 \text { (6.9): conservative } \\
\text { treatment }\end{array}$ & $7(24.1)$ & $\begin{array}{l}2 \text { (6.9): one stage reconstruction } \\
\text { (stomach,2) }\end{array}$ & $27(93.1)$ \\
\hline $\begin{array}{l}\text { Macchiarini et } \\
\text { al. [6] (2000) }\end{array}$ & 32 & $12(37.5)$ & $14(43.8)$ & $\begin{array}{l}6 \text { (18.8): indirect closure } \\
\text { with muscle flap }\end{array}$ & $3(9.4)$ & $\begin{array}{l}3 \text { (9.4): esophageal diversion } \\
\text { with second reconstruction }\end{array}$ & \\
\hline $\begin{array}{l}\text { Fiala et al. [11] } \\
(2004)\end{array}$ & 5 & 0 & $5(100.0)$ & & $5(100.0)$ & & $5(100.0)$ \\
\hline $\begin{array}{l}\text { Camargo et al. } \\
\text { [10] (2010) }\end{array}$ & 14 & 0 & $14(100.0)$ & & 0 & & 0 \\
\hline $\begin{array}{l}\text { Shen et al. [16] } \\
\text { (2010) }\end{array}$ & 35 & $28(80.0)$ & $3(8.6)$ & $\begin{array}{l}4 \text { (11.4): indirect closure } \\
\text { with muscle flap (2); } \\
\text { indirect closure with } \\
\text { esophagus (2) }\end{array}$ & $18(51.4)$ & $\begin{array}{l}17 \text { (48.6): esophageal diversion } \\
\text { without reconstruction (4); } \\
\text { esophageal diversion with } \\
\text { second reconstruction (9); } \\
\text { one-stage reconstruction (4) }\end{array}$ & $28(80.0)$ \\
\hline $\begin{array}{l}\text { Muniappan et } \\
\text { al. [7] (2013) }\end{array}$ & 36 & 14 (38.9) & $22(61.1)$ & & $20(55.6)$ & $\begin{array}{l}\text { 3: esophageal diversion without } \\
\text { reconstruction (1); end-to-end } \\
\text { esophageal anastomosis (1); } \\
\text { skin graft (1) }\end{array}$ & $36(100.0)$ \\
\hline $\begin{array}{l}\text { Marulli et al. } \\
\text { [14] (2013) }\end{array}$ & 25 & $15(60.0)$ & $8(35.0)$ & $\begin{array}{l}2 \text { (8.0): indirect closure } \\
\text { with muscle flap; in } \\
\text { direct closure with bio- } \\
\text { absorbable patch }\end{array}$ & $24(96.0)$ & $\begin{array}{l}1 \text { (4.0): end-to-end esophageal } \\
\text { anastomosis }\end{array}$ & $18(72.0)$ \\
\hline $\begin{array}{l}\text { Foroulis et al. } \\
\text { [12] (2015) }\end{array}$ & 13 & $13(100.0)$ & 0 & & $13(100.0)$ & & $13(100.0)$ \\
\hline $\begin{array}{l}\text { Bibas et al. [8] } \\
\text { (2016) }\end{array}$ & 20 & $11(55.0)$ & $9(45.0)$ & & $19(95.0)$ & $\begin{array}{l}1 \text { (5.0): esophageal diversion } \\
\text { with second reconstruction ( } 1 \text { ) }\end{array}$ & $20(100.0)$ \\
\hline $\begin{array}{l}\text { Yang et al. [17] } \\
\text { (2016) }\end{array}$ & 22 & 0 & 0 & 22 (100.0): double patch & & $\begin{array}{l}22 \text { (100.0): one-stage } \\
\text { reconstruction with stomach }\end{array}$ & 0 \\
\hline $\begin{array}{l}\text { Bolca et al. [9] } \\
\text { (2017) }\end{array}$ & 11 & 0 & $9(81.8)$ & $\begin{array}{l}\text { 2: indirect closure with } \\
\text { esophagus (1); patch } \\
\text { repair with bovine } \\
\text { pericardium (1) }\end{array}$ & $9(81.8)$ & $\begin{array}{l}1 \text { (9.1): one-stage reconstruction } \\
\text { (1); patch repair with bovine } \\
\text { pericardium (1) }\end{array}$ & $10(90.9)$ \\
\hline $\begin{array}{l}\text { Liu et al. [13] } \\
\text { (2017) }\end{array}$ & 5 & 0 & $5(100.0)$ & & $5(100.0)$ & & 0 \\
\hline $\begin{array}{l}\text { Puma et al. [15] } \\
\text { (2017) }\end{array}$ & 10 & 0 & $7(70.0)$ & $\begin{array}{l}3 \text { (30.0): trachea } \\
\text { resection of other site } \\
\text { trachea stenosis and } \\
\text { primary repair fistula }\end{array}$ & $10(100.0)$ & & $10(100.0)$ \\
\hline Present (2020) & 8 & $2(25.0)$ & $5(62.5)$ & $\begin{array}{l}1 \text { (12.5): division with } \\
\text { stapler }\end{array}$ & $6(75.0)$ & $\begin{array}{l}2 \text { (25.0): esophageal diversion } \\
\text { with second reconstruction } \\
\text { (1); division of large fistula } \\
\text { with endo- stapler }\end{array}$ & $2(25.0)$ \\
\hline
\end{tabular}

Values are presented as number (\%). Inclusion criteria: studies from 1991 to 2020 of $\geq 5$ patients undergoing surgical treatment for acquired benign tracheoesophageal fistula that reported outcomes with surgery-specific data. TREE, tracheal resection and end-to-end anastomosis.

has been reported in up to $35 \%$ of patients, and respiratory failure occurs in $>15 \%$ of cases. Considering that the surgical mortality rate is about $4 \%-5 \%$, lung-related diseases are considered to be an important factor related to mortality (Table 4). Therefore, perioperative respiratory care is an important factor for improving the survival rate.

Finally, we compared the morbidity and mortality discussed in the literature [1,6-18] (Table 4). The comparison of clinical results of small centers to those of large centers was not significant because tracheal surgery was performed 
Table 4. Postoperative results of various studies on the treatment of tracheoesophageal fistula

\begin{tabular}{|c|c|c|c|c|c|c|c|c|}
\hline \multirow[b]{2}{*}{ Reference } & \multirow[b]{2}{*}{$\begin{array}{c}\text { TEF surgery } \\
\text { per year } \\
\text { (cases/year) }\end{array}$} & \multicolumn{7}{|c|}{ No. (\%) } \\
\hline & & Morbidity & Mortality & $\begin{array}{l}\text { TEF } \\
\text { recurrence }\end{array}$ & Stenosis & $\begin{array}{c}\text { Other } \\
\text { trachea } \\
\text { problem }\end{array}$ & $\begin{array}{c}\text { Pneumonia, } \\
\text { respiratory } \\
\text { failure, or sepsis }\end{array}$ & $\begin{array}{c}\text { T-tube or } \\
\text { trache- } \\
\text { ostomy }\end{array}$ \\
\hline $\begin{array}{l}\text { Mathisen et al. [1] } \\
\text { (1991) }\end{array}$ & $2.4(38 / 12)$ & $10(26.3)$ & $4(10.5)$ & $2(5.3)$ & $1(2.6)$ & $2(5.3)$ & $3(7.9)$ & $2(5.3)$ \\
\hline $\begin{array}{l}\text { Baisi et al. [18] } \\
\text { (1999) }\end{array}$ & $1.6(29 / 18)$ & $7(24.1)$ & $1(3.4)$ & $2(6.9)$ & $1(3.4)$ & 0 & 0 & $4(13.8)$ \\
\hline $\begin{array}{l}\text { Macchiarini et al. } \\
\text { [6] (2000) }\end{array}$ & $1.6(32 / 20)$ & 7 (21.9) & $1(3.1)$ & $1(3.1)$ & $2(6.3)$ & $2(6.3)$ & $10(31.3)$ & $2(6.3)$ \\
\hline $\begin{array}{l}\text { Fiala et al. [11] } \\
\text { (2004) }\end{array}$ & $0.2(5 / 27)$ & 0 & 0 & & 0 & 0 & 0 & 0 \\
\hline $\begin{array}{l}\text { Camargo et al. [10] } \\
(2010)\end{array}$ & $0.9(14 / 15)$ & $4(28.6)$ & 0 & 0 & 0 & $2(14.3)$ & $1(7.1)$ & $5(35.7)$ \\
\hline $\begin{array}{l}\text { Shen et al. [16] } \\
\text { (2010) }\end{array}$ & $1.2(35 / 30)$ & 19 (54.3) & $2(5.7)$ & $3(8.6)$ & $2(5.7)$ & $2(5.7)$ & $12(34.3)$ & $2(5.7)$ \\
\hline $\begin{array}{l}\text { Muniappan et al. } \\
\text { [7] (2013) }\end{array}$ & $1.9(36 / 19)$ & 20 (55.6) & $1(2.8)$ & $4(11.1)$ & $1(2.8)$ & $2(5.6)$ & $4(11.1)$ & $10(27.8)$ \\
\hline $\begin{array}{l}\text { Marulli et al. [14] } \\
(2013)\end{array}$ & $2.5(25 / 10)$ & $8(35.0)$ & 0 & 0 & $1(4.0)$ & $2(8.0)$ & $3(12.0)$ & $2(8.0)$ \\
\hline $\begin{array}{l}\text { Foroulis et al. [12] } \\
\text { (2015) }\end{array}$ & $1.9(13 / 7)$ & $4(30.8)$ & $3(23.1)$ & $1(7.7)$ & 0 & 0 & $3(23.1)$ & $1(7.7)$ \\
\hline $\begin{array}{l}\text { Bidas et al. [8] } \\
\text { (2016) }\end{array}$ & $1.3(20 / 15)$ & 11 (55.0) & $1(5.0)$ & $1(5.0)$ & $3(15.0)$ & $1(5.0)$ & $4(20.0)$ & $2(10.0)$ \\
\hline $\begin{array}{l}\text { Yang et al. [17] } \\
\text { (2016) }\end{array}$ & $2.2(22 / 10)$ & $4(18.2)$ & 0 & 0 & 0 & $1(4.5)$ & $1(4.5)$ & \\
\hline $\begin{array}{l}\text { Bolca et al. [9] } \\
\text { (2017) }\end{array}$ & $1.1(11 / 10)$ & $2(18.2)$ & $2(18.2)$ & 0 & 0 & 0 & 0 & $2(18.2)$ \\
\hline Liu et al. [13] (2017) & $1.0(5 / 5)$ & 0 & 0 & 0 & 0 & 0 & 0 & 0 \\
\hline $\begin{array}{l}\text { Puma et al. [15] } \\
\text { (2017) }\end{array}$ & $0.7(10 / 15)$ & $5(50.0)$ & $1(10.0)$ & $1(10.0)$ & 0 & 0 & 0 & $4(40.0)$ \\
\hline Present (2020) & $0.9(8 / 9)$ & $4(50.0)$ & 0 & $1(12.5)$ & $1(12.5)$ & $2(25.0)$ & 1 (12.5) & $2(25.0)$ \\
\hline
\end{tabular}

Inclusion criteria: studies from 1991 to 2020 of $\geq 5$ patients undergoing surgical treatment for acquired benign tracheoesophageal fistula that reported outcomes with surgery-specific data.

in $<2$ cases per year (range, $0.2-2.5$ cases) at most institutions. However, for centers with $<1$ case annually compared to centers with $>1$ case annually, the morbidity was $16 \%$ versus $25 \%$ and the mortality was $5 \%$ versus $4.7 \%$. In our study, 4 cases of morbidity occurred. There was 1 case each of TEF recurrence, tracheal granulation, tracheal dehiscence, and stenosis of the esophagus. For treatment of stenosis of the esophagus, dilatation is performed using a balloon or bougination. In cases of dehiscence or granulation, stent insertion or re-tracheostomy was performed for treatment. In the case of recurrence of TEF after primary repair, TREE was performed. However, due to the limited number of cases and the lack of published results, it is difficult to draw conclusions regarding the surgical outcomes. Therefore, the differences in surgical results may have been due to slight differences among centers, but overall, it is suspected that surgical volume may not be an important factor. It has been proposed that although an institution may experience a small volume of TEF surgery, if the institution has a well-trained surgical team and supporting system and the surgical procedures are performed in strict adherence to a standard surgical policy, the surgical results will be consistent and excellent.

In conclusion, TEF often requires surgical treatment, and treatment relying on spontaneous closure or an intervention is limited. Irrespective of the number of cases and the complexity of surgery, satisfactory surgical results will be obtained if an institution has a well-trained surgical team and a good support system that takes care of patients appropriately. 


\section{Conflict of interest}

No potential conflict of interest relevant to this article was reported.

\section{Funding}

This work was supported by a 2-Year Research Grant of Pusan National University.

\section{ORCID}

Sang Pil Kim: https://orcid.org/0000-0001-8110-8432

Juhyun Lee: https://orcid.org/0000-0003-3614-966X

Sung Kwang Lee: https://orcid.org/0000-0002-5015-9277

Do Hyung Kim: https://orcid.org/0000-0002-8774-3397

\section{References}

1. Mathisen DJ, Grillo HC, Wain JC, Hilgenberg AD. Management of acquired nonmalignant tracheoesophageal fistula. Ann Thorac Surg 1991;52:759-65

2. Dartevelle P, Macchiarini P. Management of acquired tracheoesophageal fistula. Chest Surg Clin N Am 1996;6:819-36.

3. Debourdeau A, Gonzalez JM, Dutau H, Benezech A, Barthet M. Endoscopic treatment of nonmalignant tracheoesophageal and bronchoesophageal fistula: results and prognostic factors for its success. Surg Endosc 2019;33:549-56.

4. Santosham R. Management of acquired benign tracheoesophageal fistulae. Thorac Surg Clin 2018;28:385-92.

5. Grillo HC, Moncure AC, McEnany MT. Repair of inflammatory tracheoesophageal fistula. Ann Thorac Surg 1976;22:112-9.

6. Macchiarini P, Verhoye JP, Chapelier A, Fadel E, Dartevelle P. Evaluation and outcome of different surgical techniques for postintubation tracheoesophageal fistulas. J Thorac Cardiovasc Surg 2000;119: 268-76.

7. Muniappan A, Wain JC, Wright CD, et al. Surgical treatment of nonmalignant tracheoesophageal fistula: a thirty-five year experience. Ann Thorac Surg 2013;95:1141-6.

8. Bibas BJ, Guerreiro Cardoso PF, Minamoto H, et al. Surgical man- agement of benign acquired tracheoesophageal fistulas: a ten-year experience. Ann Thorac Surg 2016;102:1081-7.

9. Bolca C, Pavaloiu V, Fotache G, et al. Postintubation tracheoesophageal fistula: diagnosis, treatment and prognosis. Chirurgia (Bucur) 2017;112:696-704.

10. Camargo JJ, Machuca TN, Camargo SM, Lobato VF, Medina CR. Surgical treatment of benign tracheo-oesophageal fistulas with tracheal resection and oesophageal primary closure: is the muscle flap really necessary? Eur J Cardiothorac Surg 2010;37:576-80.

11. Fiala P, Cernohorsky S, Cermak J, Patek J, Krepela E, Mouckova M. Tracheal stenosis complicated with tracheoesophageal fistula. Eur J Cardiothorac Surg 2004;25:127-30.

12. Foroulis CN, Nana C, Kleontas A, et al. Repair of post-intubation tracheoesophageal fistulae through the left pre-sternocleidomastoid approach: a recent case series of 13 patients. J Thorac Dis 2015;7 (Suppl 1):S20-6.

13. Liu J, Wu W, Liu S, Xu Z, Wang J, Li B. A modified tracheal transaction approach for the repair of nonmalignant tracheoesophageal fistulas: a report of 5 cases. ORL J Otorhinolaryngol Relat Spec 2017;79:147-52

14. Marulli G, Loizzi M, Cardillo G, et al. Early and late outcome after surgical treatment of acquired non-malignant tracheo-oesophageal fistulae. Eur J Cardiothorac Surg 2013;43:e155-61.

15. Puma F, Vannucci J, Santoprete S, et al. Surgery and perioperative management for post-intubation tracheoesophageal fistula: case series analysis. J Thorac Dis 2017;9:278-86.

16. Shen KR, Allen MS, Cassivi SD, et al. Surgical management of acquired nonmalignant tracheoesophageal and bronchoesophageal fistulae. Ann Thorac Surg 2010;90:914-9.

17. Yang G, Li WM, Zhao JB, et al. A novel surgical method for acquired non-malignant complicated tracheoesophageal and bronchial-gastric stump fistula: the "double patch" technique. J Thorac Dis 2016;8:3225-31.

18. Baisi A, Bonavina L, Narne S, Peracchia A. Benign tracheoesophageal fistula: results of surgical therapy. Dis Esophagus 1999;12:20911.

19. Dhiwakar M, Ronen O, Supriya M, Mehta S. Surgical repair of mechanical ventilation induced tracheoesophageal fistula. Eur Arch Otorhinolaryngol 2020;277:323-31. 